\title{
Chapter 18 Hemispheric Asymmetries in the Brain
}

Brain activities regarding knowledge and behavior are reflexive of scientific steps and human knowledge. Behavior is explored deeply only after scientific measurements of brain actions in both hemispheres.

In these pages was born one of the most intense analyses on all the ways that the two hemispheres of the brain affect human behavior.

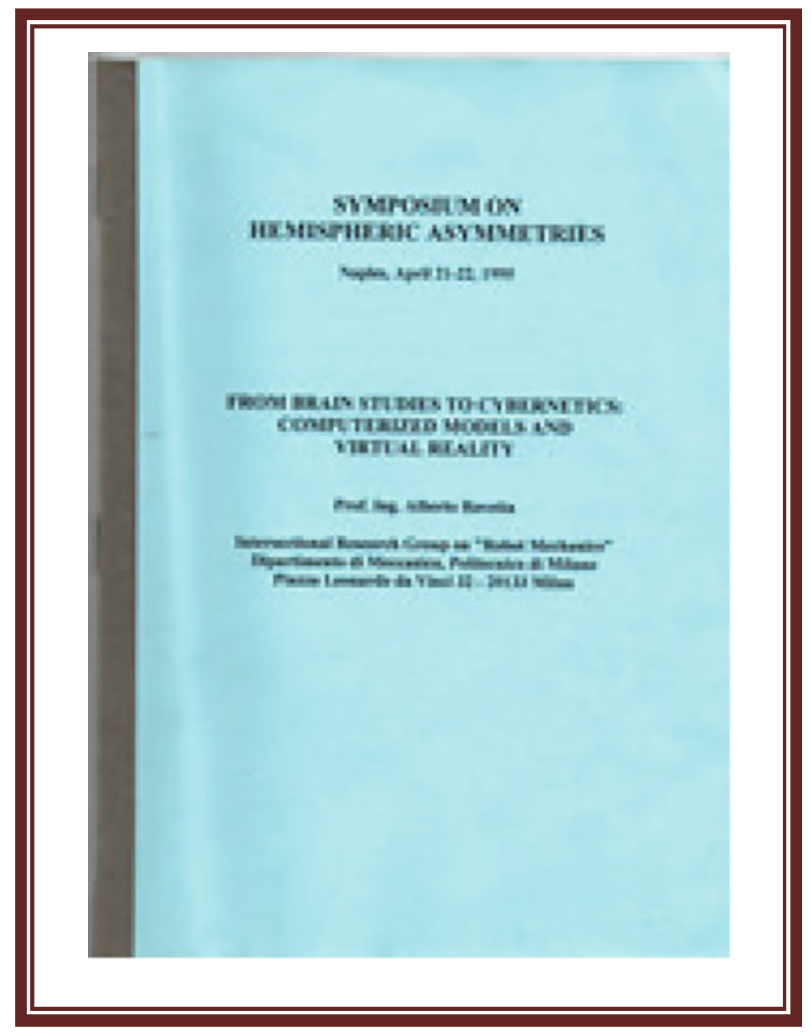

